\title{
Analysis on the Problems and Countermeasures of E-commerce Credit System and Credit Management
}

\author{
Yongliang $\mathrm{Li}^{1,2} \mathrm{a}^{*}$ and Yaqin $\mathrm{Liu}^{1}$ \\ ${ }^{1}$ Luoyang Normal University, Luoyang, 471934, China \\ ${ }^{2}$ Henan key Laboratory for Big Data Processing \& Analytics of Electronic Commerce, Luoyang, \\ 471934, China
}

aliyongliangls@163.com

Keywords: E-commerce; Credit Management; Security; Problems and Countermeasures; Law

\begin{abstract}
To solve the credit problem of e-commerce, we should start with the construction of e-commerce credit system. The construction of credit system is a huge and complex system project, which must be cooperated by government, industry, enterprises, consumers and media. This paper analyzes the credit problems existing in e-commerce in China. The paper presents analysis on the problems and countermeasures of E-commerce credit system and credit Management. Therefore, the social credit system based on honesty and credit should be built up step by step, so as to create a good atmosphere of electronic commerce market, establish the confidence of consumers and promote the rapid development of electronic commerce.
\end{abstract}

\section{Introduction}

We need to synthesize the relevant data before we can evaluate the credit rating of e-commerce. Business transactions are usually regulated by the industry and commerce department, which sets up an online bureau for industry and commerce, receives online complaints, receives tax, environmental protection, judicial and even consumer data, and then evaluates the credit rating of the enterprise according to these data.

In the face of these problems, we have to make us think deeply. These problems arise because of the human moral behavior, the technical problems in electronic commerce, and the unsound laws and regulations. I think it comes down to the fact that the emergence of these problems can be said to be that the credit system of the electric sub business is not in place or that it plays a role. It's not reached.

E-commerce, literally, is a way of doing all kinds of business using modern electronic technology. The essence of e-commerce should be a complete set of network commerce and management information system [1]. More specifically, it is the use of existing computer hardware equipment, software and network infrastructure, through a certain protocol connected by the electronic network environment for all kinds of business activities. This is a more strict definition, to say a bit more popular, e-commerce generally refers to the use of the Internet for business activities, such as: online marketing, online customer service, as well as online advertising, online surveys, and so on.

To build such a network service open logistics industry credit platform, the most important solution to the soft and hard infrastructure problems. The hard foundation of logistics credit platform mainly refers to the accurate information collection device and identification device in intelligent logistics. The main work in the stage of cargo identification is to arrange the identification device of goods uniformly; to promote the application of electronic seal, intelligent lock and turnover box in logistics; and to realize the identification and authentication of transport tools and goods of logistics object. Ensure information interaction and identification of logistics credit platform. The soft foundation of the logistics credit platform mainly refers to the logistics intelligent software system, which acts as the "heart" and "nerve" of the logistics system environment, and is the center to ensure the safe and reliable operation of the logistics credit platform in many application fields.

$\mathrm{B} 2 \mathrm{~B}$ is the exchange of products, services and information between enterprises and enterprises via the Internet. The traditional inter-firm transaction often consumes a lot of resources and time, whether 
it is sales, distribution or procurement, it takes up the cost of products. Through B2B trading, buyers and sellers can complete the entire business process online, from building initial impressions to comparing goods, to bargaining, signing orders and delivering goods. Finally, it is to customer service. B2B makes the transaction between enterprises reduce many transactional workflow and management costs, and reduce the operating cost of the enterprise. The convenience and extensibility of the network makes the enterprise expand the range of activities, and the development of the enterprise across borders is more convenient and the cost is lower. With the help of B2B e-commerce platform, enterprises do not need too much expertise and a large amount of capital investment, and they may also get considerable profits.

According to the survey, about $60 \%$ of the people have encountered personal information by the website or online sellers spread at will, such as personal name, contact information and so on. The spread of this information will cause lasting harm to users, and then will affect the confidence of users in e-commerce, and these effects are difficult to eliminate in a short period of time. It is precisely because of these dishonest behaviors of websites or online merchants that greatly hinder the healthy development of electronic commerce. To change this situation, it is necessary to establish an effective credit system of electronic commerce.

\section{Significance of Speeding up the Construction of Electronic Commerce Credit System}

Customers want to be able to e-commerce $24 \times 7$ all-weather services. A failure in operation can have serious consequences. A major online auction house, for example, saw its stock value fall by $18.8 \%$ after three failures is on its website in five days (including a 22-hour outage) [2]. E-commerce companies can increase their flexibility in uncertainty management by building emergency capacity, enhancing redundancy and implementing a monitoring program that provides early warning of capacity overload, involving planning, decision-making, implementation, and monitoring. To ensure that daily operations provide effective and efficient expected results.

The authenticity and legitimacy of the subject is e-commerce transaction. It is difficult to identify the authenticity of the registration of e-commerce traders. Especially in B2CU C2CU B2B2C, the rules and management methods can not identify whether some trading subjects are real or anonymous. In transactions, the anonymous identity subject is hardly restricted by the transaction rules, which increases the credit risk of other parties in the transaction. Moreover, the authenticity of the transaction subject can not be guaranteed, as is shown by equation (1), which is one of the reasons why it is difficult to execute the electronic contract [3].

$$
x(k+1)=\left[\begin{array}{cc}
0.96 & 0.5 \\
0 & 1
\end{array}\right] x(k)+\left[\begin{array}{c}
0.1 \\
1
\end{array}\right] w(k)
$$

Market economy is a kind of credit economy, a kind of legal economy. A complete legal system of credit management is an inevitable requirement for the healthy and normative development of credit industry. The breach of credit that causes damage to other parties in commercial activities should be punished by the law. Therefore, we should constantly improve the existing legal system, for example, in the process of formulating or revising relevant laws and regulations, such as the Patent Law, the Trademark Law, the copyright Law, the Anti-unfair Competition Law, the contract Law, the Company Law, the Bill Law, etc. Fully consider the characteristics of electronic commerce, create a good legal environment for the development of electronic commerce and leave room for development.

The economy of our country has experienced a process from planned economy to market economy, the social credit economy has begun relatively late, the market credit transaction is not developed, and the society generally lacks the credit consciousness and credit moral standard under the modern market economy condition. The credit consciousness of enterprises and individuals is weak; some enterprises still develop very well without credit, so the phenomenon of credit deficiency is very common. This to e-commerce credit produced a very disadvantageous restriction effect. The network itself is a virtual platform, which to a large extent tests the integrity of participants. In an invisible market, dealing with an 
invisible merchant or a strange customer makes consumers or enterprises feel insecure and reject e-commerce.

$\mathrm{Xml}$ is a standard platform-independent data format, and web service itself has the characteristics of cross-hardware, cross-network, cross-operating system, etc. The system can traverse the firewall transparently and realize the interaction between data and services across platforms. Therefore, the system has extensive platform interoperability.

The mode of surety is characterized by the guarantee provided by the website or the operating enterprise of the website, which attempts to solve the credit risk problem through this guarantee. The biggest benefit of this kind of credit model which regards the website or website's sponsor as a guarantee agency is that the credit risk is reduced but the liability of the website and website operator is increased. And the guarantee process, there is a verification of the negotiation process, the equivalent of an invisible increase in transaction costs. Therefore, in practice, this credit model is generally only applicable to specific organizational industries.

\section{Analysis of Credit Status and Problems in E-commerce in China}

At present, our country is still in the economic transition period, the market is still immature, the social credit system is not perfect, the market economy system and the market mechanism are not standard and perfect, and the perfect credit system has not been established. From the process of electronic commerce: information, transaction, payment, logistics and other aspects of every link there is credit risk, each trading object also has a credit risk. However, while seeing that foreign developed countries obtain excess profits from the management of electronic commerce, our country blindly copied foreign electronic commerce, but did not take into account the actual situation of our country or the present situation of our country's credit system. So that there are many obstacles, e-commerce activities in many cases can not run smoothly.

Electronic signature collection is the logistics industry according to its own characteristics and development needs, a series of Internet of things technology through the system integration development and application, in order to improve the utilization of enterprise resources and productivity level. To guard against the instability of business flow is to strengthen the level of business process control [4]. The traditional paper transfer method not only spends a lot of paper and manpower, but also can not meet the needs of the growing logistics management.

To identify the identity of the receiving / delivering party and the transport vehicle and whether the goods are consistent with the destination through RFID, as is shown by equation (2), to scan the bar code information of the commodity vehicle to confirm the identity and the quality of the goods vehicle, etc., and to form a unique digital signature together with each time the goods are handed over. Through the GPRS communication network, transmission to the logistics credit platform, timely update of the completion of the order handover status. At the same time, the platform in the first time by SMS or telephone to notify the relevant stakeholders. The platform will automatically parse, verify and respond to complete signature information management.

$$
\left[\begin{array}{l}
u_{-K} \\
\vdots \\
u_{K}
\end{array}\right]=M\left[\begin{array}{lll}
j^{-K} J_{-K}(-\beta) & 0 & 0 \\
0 & \ddots & 0 \\
0 & 0 & 0
\end{array}\right]\left[\begin{array}{ccc}
\exp \left(-j K \theta_{1}\right) & \cdots & \exp \left(-j K \theta_{N}\right) \\
\vdots & \cdots & \vdots \\
\exp \left(j K \theta_{1}\right) & \cdots & \exp \left(j K \theta_{N}\right)
\end{array}\right]\left[\begin{array}{c}
s_{1} \\
\vdots \\
s_{N}
\end{array}\right]
$$

The e-commerce of our country starts late, but develops rapidly. Large B2B websites, such as Alibaba, Global Resources, Huicong, Maimai, Asian-American online, Wanguo Business Network, World E-Commerce Network, China Manufacturing Network, etc., have launched their business in succession, as well as numerous small and medium-sized B2B websites. The number of B2B websites in China is growing in geometric numbers. At the same time, E-commerce and Internet complement each other. Because of the large number of Internet users in China, it provides a good basis for the development of E-commerce in China. 
Honesty and trustworthiness have become the basis of maintaining the credit relationship between e-commerce enterprises and users, and are also the fundamental ways for e-commerce enterprises to win the competition. The credit discredit of the electronic commerce market in our country is serious and has become a "bottleneck" restricting the growth of the industry. The fundamental reason lies in the fact that our country has not yet established and perfected the social credit system. To sum up, the significance of establishing e-commerce credit system is that it is beneficial to the establishment of enterprise credit management system. E-commerce among enterprises is the main body of e-commerce transactions. The credit management system of enterprises includes the credit management of e-commerce. The construction of e-business credit system will promote the scientific and standardized credit management system of enterprises. To promote the rapid and healthy development of e-commerce is transactions and the need to enhance the international competitiveness of enterprises.

The commodity information risk is in the e-commerce transaction. In e-commerce transactions, the only intuitive understanding of goods by consumers is the information obtained from pictures of goods and online communication with the other side of the transaction. If there is a problem of integrity on the part of the provider of the goods, they deliberately obscure the information of the goods or provide false information. Existing regulations and technologies can not verify the authenticity, validity and integrity of online commodity information, which is also a major factor of credit risk in e-commerce.

\section{Analysis on Credit System of E-commerce and Countermeasures of Credit Management}

The predecessor of the enterprise credit system is Bank Credit Registration and Consultation System, which was established in 1997 and established in 2002. The system mainly collects the basic information of enterprises from financial institutions such as commercial banks, credit information such as loans and guarantees of financial institutions, and the main financial indexes of enterprises.

In the real society, fake and shoddy goods are rampant, hypocritical advertisements are flooding, the contract performance rate is low, managers lack of good faith, credit card decoy, poor recovery of debts and other good faith problems appear in the newspaper every day, almost become a widespread phenomenon; However, as a transaction mode without seeing each other, e-commerce is even more difficult to obtain the approval of consumers. The idea of "no business, no traitors" is deeply rooted in people's minds. Enterprises and enterprises, enterprises and consumers, and people are more alert than trustworthy. Both are the psychological barriers to the development of e-commerce.

The direct economic benefits of enterprises and consumers have been lost. As a result of the dishonest behavior in the transaction, the enterprise and the consumer's economic benefit suffer the different degree loss. Consumers who issue orders for non-payment, receive goods, or pay in time, and return goods without any reason will increase the operating costs of the enterprises; the enterprises provide false information, receipts, do not deliver goods or do not deliver goods in time, and do not support normal returns, as is shown by equation(3) [5]. Failure to provide good after-sales service, low quality logistics will make consumers suffer losses.

$$
a(i)=P_{1}(i, j) / P_{1}(i,(j+\text { span }))
$$

The construction of electronic commerce credit system must begin with the credit system construction of the whole society, and the construction of social credit system is a huge and complex system project, which must be carried out by the government, industry and enterprises. The cooperation of all aspects of consumers and media is supported by morality, protected by law, and realized by scientific organization and management system as well as advanced technical means. Secondly, E-commerce enterprises must reasonably standardize their own organizational structure, innovate in management, and form a set of perfect integrity system within e-commerce enterprises by combining effective technology.

To improve the means of payment in electronic commerce, e-commerce transactions need information flow, logistics and capital flow at the same time, so we must improve the electronic payment system, improve the electronic payment level of banks, establish a safe and strict, A reliable social range 
of electronic money payment system, and the establishment of e-commerce certification agencies, as soon as possible to set up a unified online settlement center, and gradually develop online settlement services with foreign customers.

The third party payment is based on the bank's service, cooperates with the bank, provides the individualized electronic payment service to the large and small enterprises, and develops the user-oriented value-added service for the bank. Due to benefit neutrality and open business model, third-party payment can satisfy the change of business model of different enterprises and help merchants to create more value. Improving third-party payment requires policy supervision and support from the central bank, while the technology update industry must keep up.

\section{Summary}

Establish a system of credit evaluation and supervision of enterprises and individuals with banks, business administration, public security and tax departments, such as establishing a credit rating system shared by e-commerce enterprises. The alliance, which has the role of the industry association, will merge the data of the respective credit records of each e-business enterprise. The enterprise and individual subject to the Internet transaction will eventually have a permanent credit card number that is generally applicable on the Internet, and the online transactions will be recorded in this card. Become the clear mark of the main credit rating of the main body.

\section{Acknowledgements}

This paper is supported by the key Scientific Research Project Plan of Henan Province (17A880020).

\section{References}

[1] Liao Junfeng, Chen Liping, The Credit problem in Electronic payment and its Social Root, Academic research. 2014(11): 79-88.

[2] Luo Hong, Research and Application of Electronic Commerce based on web Services, Chongqing: Sichuan University, 2013:34-54.

[3] Bai Zhenwu, The problems and Countermeasures of developing Network Marketing in small and Medium-sized Enterprises, Coastal Enterprises and Science and Technology. 2014(5): 188-189.

[4] Cai Sainan, Reflections on the opening and sharing of Credit Information in the Construction of Credit Information system in China, Credit information. No. 2011, 29(2): 251-254.

[5] Zhang Ran, Yao Xiaolei, Major obstacles and policy analysis affecting the development of e-commerce in small and medium sized enterprises, business information. 2016, (12):121-125. 